\title{
Cabins and Islands: A Fire Protection Strategy for an International Airport Terminal Building
}

\author{
PAULA BEEVER \\ Arup Research \& Development \\ 13 Fitzroy Street, London W1P 6BQ, UK
}

\begin{abstract}
For architectural and functional reasons, transport terminal buildings are frequently designed to incorporate large uncompartmented spaces. Fire resisting walls as means of limiting fire and smoke spread within these large spaces are therefore absent. This paper shows how fire safety may be achieved nevertheless for the case of a very large airport terminal building to be built in Osaka Bay in Japan.
\end{abstract}

The fire safety strategy relies essentially on two designed features. The first of these is that the areas of high fire load such as shops are limited in extent and well defined. It was proposed therefore that these areas should be protected separately by sprinklers and provided with a dedicated smoke extract on system. This is known as the "cabin concept". Secondly, areas of combustible material, including seating, tend to be well separated with large circulation spaces in between. By considering radiation from a severe fire in each such area, it was shown that fire spread between them was not a problem. This was termed the "island concept".

This paper describes the calculations carried out and the results obtained. The design fires adopted, and many of the calculation procedures used were taken from the new Japanese Integrated Design Method for Fire Protection.

KEYWORDS: FIRE PROTECTION; COMPARTMENTATION; AIRPORT; TRANSPORT; RADIATION; SPRINKLER PROTECTION; SMOKE CONTROL

\section{INTRODUCTION}

Recent designs for international airport terminal buildings have made use of very large uncompartmented spaces. These allow easy movement of people and give a desirable sense of space. From the fire safety point of view, high ceilings can provide very large smoke reservoirs, and the open nature of the spaces can ensure clear access to exits. On the other hand, the absence of compartment walls means that additional consideration must be given to the question of how smoke and fire spread are to be controlled. 
The present paper discusses aspects of this last problem in the context of a new airport terminal building. This facility is being constructed to serve the Kansai region of Japan and will handle 25 million passengers per year. The main public areas form a series of interconnected spaces which present a need for fire engineering calculations to demonstrate safety.

\section{LAYOUT OF THE TERMINAL BUILDING}

The main terminal building (MTB) is designed on four levels: a cross-section is shown in Figure 1. Within the region designated $\mathrm{B}$ it was largely possible to implement fire protection measures as specified under Japanese Building Standard Law. This region includes shops, restaurants, offices and baggage reclaim and handling facilities.

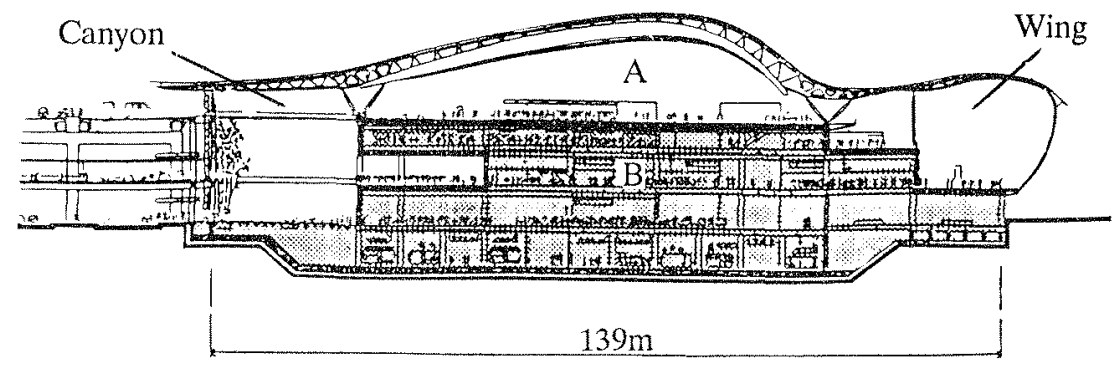

\section{FIGURE 1. Cross section through terminal building}

The present paper deals with the region labelled $A$. The arrivals concourse or Canyon is $280 \mathrm{~m}$ long and $26 \mathrm{~m}$ high. It provides access to the building from the landside and allows transfer between all levels; bridges cross the Canyon at heights of approximately $7 \mathrm{~m}$ and $19 \mathrm{~m}$ above the floor. These allow access to the domestic departure lobby on the 2 nd level and to the international departures concourse on the 4th level. This 4 th level lies under a vast curved roof and is about $80 \mathrm{~m}$ wide by $280 \mathrm{~m}$ long. At its peak, the roof is about $20 \mathrm{~m}$ above the floor. Airside boarding lounges are located in the Wing. This adjoins the main terminal building at 2 nd and 3 rd levels and extends in both directions to provide gate lounges and airside access for arriving passengers. The Wing is some $1700 \mathrm{~m}$ in length and ranges in height from $20 \mathrm{~m}$ at the centre to about $6 \mathrm{~m}$ at the ends.

Each of these spaces, even if disconnected is enormously greater in volume than would be allowed under the compartmentation rules in Japanese Building Standard Law. It was necessary therefore to demonstrate that an adequate level of fire and smoke control could be achieved in other ways.

\section{FIRE PROTECTION STRATEGY}

Several features of the building design were identified which could be exploited in order to reduce the chance of smoke and fire spread. The first of these is that areas of high fire load are limited in extent and well defined. These were identified as shops, concessions and duty free areas and check-in desks. It is possible to provide such areas with local sprinkler protection and smoke extraction systems.

In the open concourse spaces the fire load is low, consisting of seating, small information desks and passengers' baggage. In most areas the very high ceiling 
provides a more than adequate reservoir for containing smoke from the relatively small fire which might occur. A separate study, to be described elsewhere, was carried out to consider safety from smoke of those escaping.

The building of its nature has space for circulation between areas of fixed combustible material. If these are sufficiently widely separated, then fire spread from an uncontrolled fire in an unprotected area (or in a sprinkler protected area in the event that the sprinkler system failed), may be shown to be unlikely.

\section{JAPANESE INTEGRATED DESIGN GUIDE}

Wherever possible in developing the fire strategy for this building, note was taken of the approaches suggested in the Japanese Integrated Design Guide for Fire Protection[1]. This was a new publication at the time that the project commenced. It is perhaps unique in providing a complete and coherent approach to many aspects of fire protection in buildings, and relies on research work carried out all over the world. Though at the time of writing it has no legal status in Japan, it nevertheless provided a good starting point for many of the analyses which were carried out and its use was noted with interest in negotiations with the authorities.

\section{DESIGN FIRES}

For design of fire safety measures, use was made of two of the 'design fires' proposed in the Japanese Integrated Design Guide (JIDG). These were designated Type 1 and Type 2. Both fires are growing in the early stages and become steady after a defined period of time. The growth phases are composed of two linear regions, shown in Table 1.

\begin{tabular}{|c|c|c|c|}
\hline Design Fire Type & time/s & $\begin{array}{c}\text { Rate heat release/ } \\
\mathrm{kW}\end{array}$ & Fire area $/ \mathrm{m}^{2}$ \\
\hline \hline 1 & 0 & 0 & 0 \\
& 120 & 300 & 1.7 \\
& 240 & 3000 & 1.7 \\
\hline 2 & 0 & 0 & 0 \\
& 120 & 750 & 0.5 \\
& 320 & 25,000 & 17 \\
\hline
\end{tabular}

TABLE 1. Summary of Japanese Type 1 and Type 2 design fires.

The Type 1 fire is recommended in the JIDG as being for fires in general areas where the occupants are awake. The growing phase may be compared to the "fast" fire as developed by workers in the US[2]. This has a parabolic growth description: the rate of heat release increasing as the square of the time. Based on experimental work, it has been found to apply well to various types of upholstered furnishings, and stacked plastic goods. Figure 2 shows a comparison between the Type 1 fire and the fast fire. For the open areas and check-in desks, an analysis of possible fire loads was carried out, based on measurements made previously for other airports, which yielded a figure of about $12 \mathrm{~kg} \mathrm{~m}^{2}$ wood equivalent. Based on this, it was shown that the 
Type 1 fire was a conservative but not unreasonable model for fires in seating or baggage.

The Type 2 fire is recommended in the JIDG for use in shops. This may be compared with the "ultrafast" fire found to be appropriate for higher stacks and for highly flammable plastic goods in experimental work in the US. These two fires are also shown in Figure 2. The design fires proposed in the JIDG seem therefore to accord well with growth rates which might be expected from other sources for particular fire loads. For the areas identified as being of high fire load, duty free areas, concessions and shops, the Type 2 fire was chosen for design purposes.

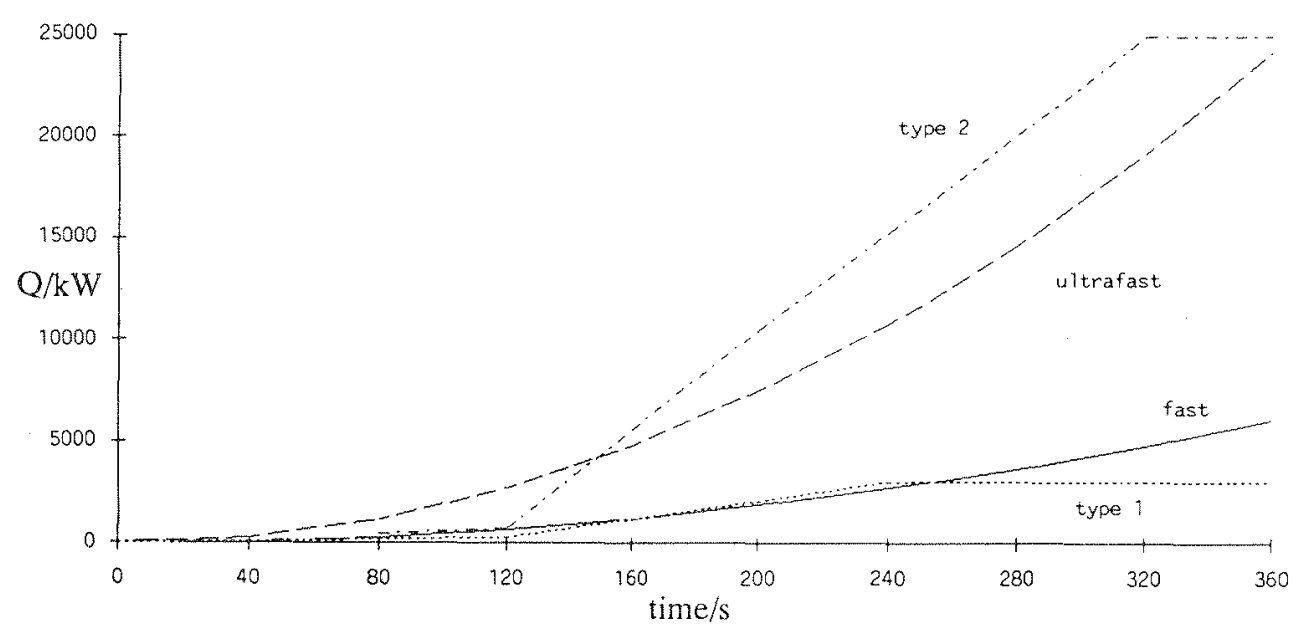

FIGURE 2. Comparison of Type 1 and Type 2 fires with fast and ultrafast fires

\section{CABIN CONCEPT}

\section{Principle of Concept}

The purpose of the Cabin Concept was to protect areas of high fire load in the concourses such that fire spread and smoke flow from these areas was controlled. The Cabin Concept requires that the area to be protected is covered by a ceiling to support a sprinkler system and provide a smoke reservoir. The cabins were, however, open sided. The smoke extraction system was designed to remove the expected volume of smoke and to prevent smoke flow into the open areas.

\section{Sprinkler Operation}

For the design of a smoke extraction system, the fire size was assumed to be controlled at a steady rate following the operation of the first sprinkler. For the low ceiling heights under discussion here, this is almost certainly a conservative assumption. The time to sprinkler operation was predicted using the US National Institute of Standards and Technology program DETACT. This software predicts the 
temperature and velocity in the fire ceiling jet and goes on to calculate the temperature of a sprinkler in relation to its position in response to a steady or slowly growing fire.

The ceiling jet predictions are based on Alpert's correlations[3]. These equations were derived from theoretical consideration and experimental work on steady fires beneath unconfined ceilings. Under practical conditions of relatively limited confined ceilings, a hot gas layer will accumulate after a period of time below the ceiling jet. Evans [4] presents a theoretical analysis which shows that this will result in an increase in the temperature and velocity of the fire gases in the ceiling jet. The use of the unconfined equations in DETACT leads therefore to an underestimate of sprinkler temperature and an overestimate of time to operation. A margin of safety is therefore introduced.

A different situation arises if the equations are used for growing rather than steady fires. A finite time elapses before gases from a fire reach the sprinkler location. For a growing fire this will mean that the steady state equations underestimate the time to sprinkler response. The error is greater further from the fire. Evans gives an estimate of the error for parabolic fires. In view of the similarity between the Japanese Type 1 and Type 2 fires and the US fast and ultrafast fires, it may be assumed that the error is similar. For typical values of ceiling height, and distance to nearest sprinkler for the cabins, the error in predicted temperature rise is about $20 \%$ after $10 \mathrm{~s}$ falling to $5 \%$ within $30 \mathrm{~s}$. Since times to sprinkler operation are much longer than this, it was concluded that the steady state equations are acceptable.

The response of the sprinkler is modelled in DETACT by assuming heat is transferred to a sprinkler element which is characterised by a single sensitivity parameter, the RTI, as defined by Heskestad[5]. The heat loss from the sprinkler element to the frame and pipework is neglected. It has been shown[5] that these heat losses become important for slow sprinklers in slow fires. In the present case the fires grow rapidly and the sprinklers normally used in Japan have moderate RTI values of around $150(\mathrm{~m} . \mathrm{s})^{1 / 2}$. In view of this, any correction for heat losses was considered unjustified.

\section{Smoke Extract}

Once the fire starts to grow and the plume rises to the cabin ceiling, smoke will gradually fill the available reservoir. On detection of the smoke at ceiling level, a mechanical extraction system will be activated. The steady rate of smoke production $M$ may be calculated using an equation given by Heskestad[6]:

$$
\mathrm{M}=0.071 \mathrm{Q}^{1 / 3}\left(\mathrm{y}-\mathrm{y}_{\mathrm{o}}\right)^{5 / 3}\left[1+0.026 \mathrm{Q}^{2 / 3}\left(\mathrm{y}-\mathrm{y}_{\mathrm{o}}\right)^{-5 / 3}\right]
$$

where $y$ is the clear height between the top of the combustible material to the base of the smoke reservoir. For a conservative approach the top of the combustible was assumed to be at floor level. The variable $y_{0}$ is the virtual source of the fire and is given[6] as:

$\mathrm{y}_{0} / \mathrm{D}=-1.02+0.083 \mathrm{Q}^{2 / 5} / \mathrm{D}$

The quantity $Q$ is the convective rate of heat release from the fire. The above equation applies if the smoke layer is above the flames. Otherwise

$$
\mathrm{M}=0.0054 \mathrm{Qy} /\left(0.166 \mathrm{Q}^{2 / 5}+\mathrm{y}_{\mathrm{o}}\right)
$$


where the flame height $y_{f}$ is given by

$\mathrm{y}_{\mathrm{r}} / \mathrm{D}=-1.02+0.230 \mathrm{Q}^{2 / 5} / \mathrm{D}$

For each cabin under consideration the mass rate of smoke to be extracted was calculated using the above equations. The temperature of the smoke was estimated by assuming that all of the heat generated by the fire goes into the smoke layer. The corresponding volume extraction rate can then be calculated. Since much of the heat from the fire will be lost by radiation, the smoke production rate and the temperature will be overestimated leading to overestimates of smoke volume and a further safety margin. Some typical values calculated for particular cabin designs are shown in Table 2.

\begin{tabular}{|l|l|l|l|l|l|}
\hline \hline Cabin Use & $\begin{array}{l}\text { Design } \\
\text { Fire }\end{array}$ & $\begin{array}{l}\text { Ceiling } \\
\text { height }\end{array}$ & $\begin{array}{l}\text { Clear } \\
\text { height }\end{array}$ & $\begin{array}{l}\text { Fire size at } \\
\text { sprinkler } \\
\text { operation/kW }\end{array}$ & $\begin{array}{l}\text { Smoke } \\
\text { extract } \\
\text { rate } / \mathrm{m}^{3} \mathrm{~s}^{-1}\end{array}$ \\
\hline \hline Shop & Type 2 & 3.5 & 2.5 & 3417 & 18 \\
\hline $\begin{array}{l}\text { Check-in } \\
\text { Desk }\end{array}$ & Type 1 & 2.1 & 1.6 & 1450 & 7.6 \\
\hline
\end{tabular}

TABLE 2. Results of smoke extract estimates for typical cabins: calculations based on sprinkler of $\mathrm{RTI}=150(\mathrm{~m} . \mathrm{s})^{1 / 2}$, actuation temperature $68^{\circ} \mathrm{C}$ at a distance of $2.5 \mathrm{~m}$ from the fire.

\section{ISLAND CONCEP'T}

\section{Fire Spread}

In areas which can be sprinkler protected, the chances of fire spread away from the area of fire origin are small. There is, however, a chance that a sprinkler system might fail to control a fire. Concourse areas in this building cannot be sprinkler protected, being necessarily open for circulation purposes under very high ceilings. Additional measures must therefore be sought to ensure that uncontrolled fire spread across large areas will not occur.

Fire spread between isolated packages of fuel occurs when the heat flux impinging on the fresh fuel is sufficiently high to result in ignition. Where the fresh fuel lies outside the plume of hot gases then ignition arises as a result of heat radiation only, from the flames of the fire itself, and also from the smoke. In a small compartment, radiation from the smoke layer is of great importance and leads ultimately to flashover. In a compartment with a high ceiling the smoke layer will be cool due to the high level of entrainment in the fire plume. Radiation from the smoke will be low and the chief mode of fire spread will be direct radiation from the flames.

The heat flux required for ignition has been studied by many workers. A distinction is made between pilot ignition, where a small flame is present, and spontaneous ignition where it is not. The first of these is related to flame spread and 
the latter to fire spread over a distance, which is of importance here. For the latter case Babrauskas[7] uses a value of $20 \mathrm{~kW} \mathrm{~m}$ for ignition by radiation of upholstered furniture (compared to $10 \mathrm{~kW} \mathrm{~m}$ for ignition of light materials such as curtains, and $40 \mathrm{~kW} \mathrm{~m}^{-2}$ for $12 \mathrm{~mm}$ thick wood). The value of $20 \mathrm{~kW} \mathrm{~m}$ is suggested by Thomas as a criterion for flashover; and is slightly more conservative than values suggested by other workers.

The heat flux $F^{7}$ emitted by radiation from a hot surface at temperature $T_{1}(K)$ is given by

$\mathrm{F}=\sigma \varepsilon\left(\mathrm{T}_{1}^{4}-\mathrm{T}_{\mathrm{o}}{ }^{4}\right)$

where $T_{0}(K)$ is the surrounding temperature. The values of emissivity $\varepsilon$ appropriate to smoke and flames have been studied but here we will take all values as equal to unity as the most conservative assumption. The net heat flux is given by

$f=\phi \varepsilon\left(T_{1}^{4}-T_{2}^{4}\right)$

where $\phi$ is the configuration factor. This describes the geometrical relationship between the hot surface and the target. It is defined as the fraction of radiation leaving one surface which is intercepted by the other surface. Useful expressions are given by Tien et al[8].

\section{Flame heights}

In order to calculate the configuration factor, it is necessary to estimate the area of flame which is facing a target of fresh fuel. The worst case is that of an uncontrolled fire in an area of combustible material. Whilst equation (4) is appropriate for calculating flame heights in fires which are small, it gives very low or even negative values for fires which are extensive in area. Figure 3 shows experimental data collected from various sources by Law[9]. These include some very large fires. It can be seen that the dimensionless flame height $y_{t} / D$ correlates fairly well with the variable (R/A $V D$ ) over a wide range of fire sizes. In order to use this figure to obtain rough estimates of flame heights, it is necessary to have values for $R$. For this purpose it was assumed that a fire burns out in 1200s. This figure is used for calculations on the response of steel to fire, and is almost certainly low, given the extent of the combustible material. Though individual items might be consumed more rapidly, the worst case is to assume that the whole area is involved in fire simultaneously.

For seating areas it was shown that the fire load is about $12 \mathrm{~kg} / \mathrm{m}^{2}$. If a fire burns out in about $1200 \mathrm{~s}$ then $\mathrm{R} / \mathrm{A}_{\mathrm{i}}$ is roughly $0.01 \mathrm{~kg} \mathrm{~m}^{-2} \mathrm{~s}^{-1}$. For seating areas from about 200 to $700 \mathrm{~m}^{2}$ in area, flame heights from Figure 3 are about 1.5 to $2.5 \mathrm{~m}$. This flame was represented here by a sheet $2 \mathrm{~m}$ high at a steady temperature of $1000^{\circ} \mathrm{C}\left(\mathrm{T}_{1}\right.$ $=1273 \mathrm{~K}$ ). This is a considerable over-estimate since the temperature at the tip of a flame is around $540^{\circ} \mathrm{C}$. Though the check-in desks have slightly higher fire loads this will not greatly affect the flame height and the same approach was used for them and also for information desks.

For the shops, a significantly higher fire load may be expected. Measured values for retail areas are given by CIB[10]. For 'perfumery, toys, stationery and household items' the value given is $420 \mathrm{MJ} / \mathrm{m}^{2}$ of floor area. Assuming $12 \mathrm{MJ} / \mathrm{kg}$ of fuel this gives about $35 \mathrm{~kg} / \mathrm{m}^{2}$. Assuming once again that the fire burns out in $1200 \mathrm{~s}, \mathrm{R} / \mathrm{A}$ is about $0.03 \mathrm{~kg} \mathrm{~m}^{-5 / 2} \mathrm{~s}^{-1}$. For a concession of about $50 \mathrm{~m}^{2}$ in area this gives R/AND of 0.01 and a flame height of $5.5 \mathrm{~m}$. This was represented by a sheet of flame $5 \mathrm{~m}$ high at $1000^{\circ} \mathrm{C}$. 


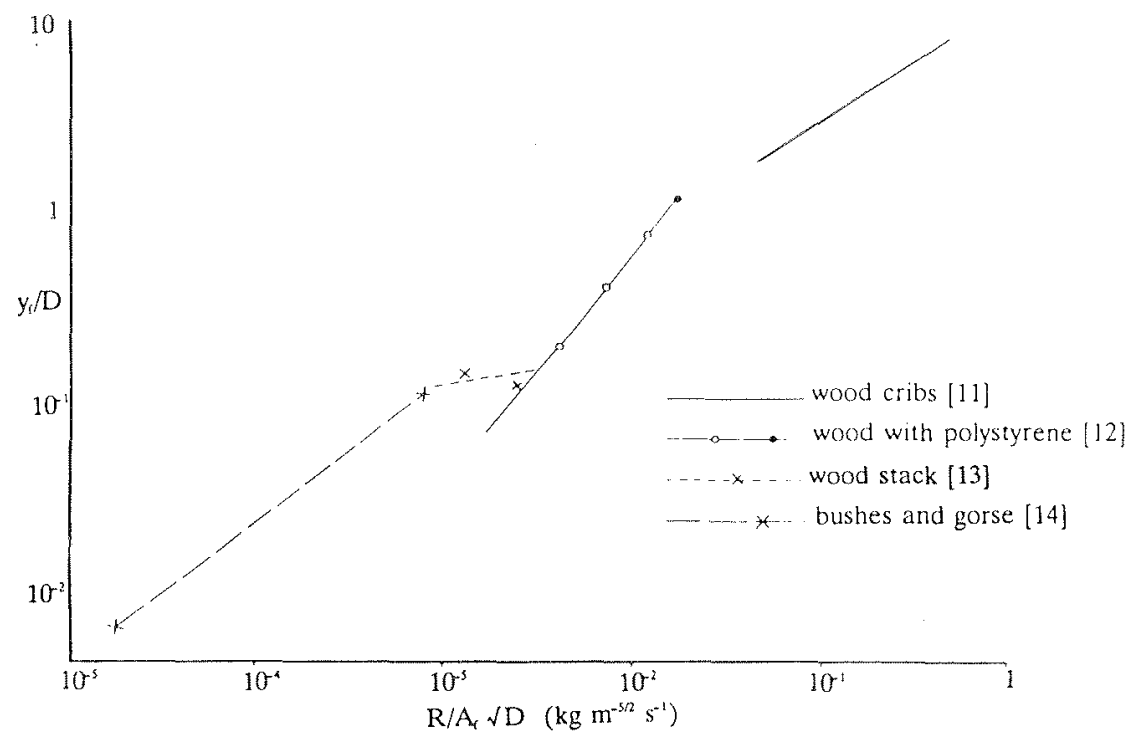

FIGURE 3. Flame heights for a range of fire sizes

\section{Resulting Islands}

Following the procedure outlined above it was possible by calculating relevant configuration factors to plot a $20 \mathrm{~kW} \mathrm{~m}$ contour around each area of combustible material. It was assumed that outside of this contour ignition and fire spread would not occur. The procedure outlined is extremely simplified but is expected to be very conservative. Better estimates could be obtained by using improved models for fully developed fires in open areas and of radiation from smoke and flames. However, the additional effort was thought to be unjustified in the present case.

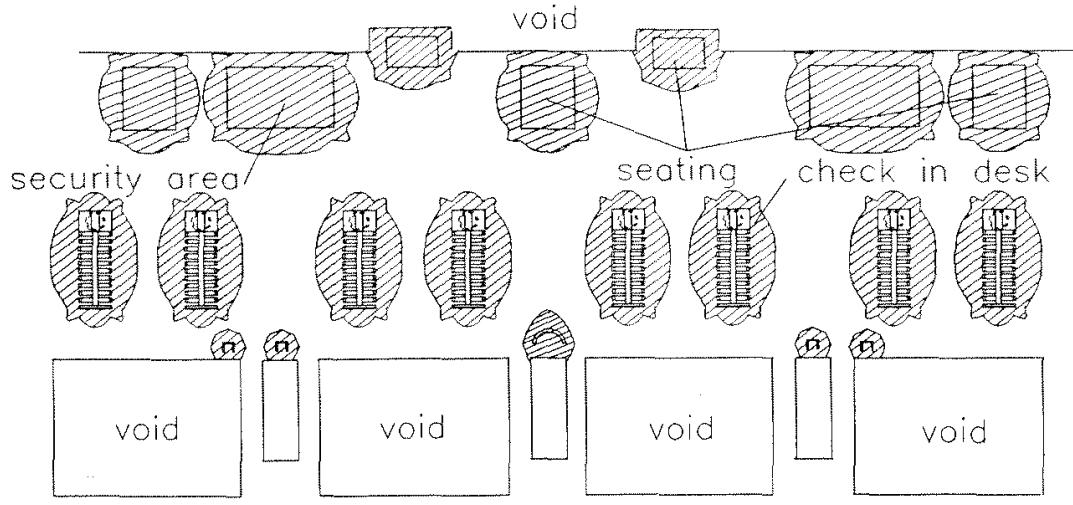

FIGURE 4. A simplified plan of the MTB Level 4. Shaded areas indicate heat flux $>20 \mathrm{~kW} \mathrm{~m}^{-2}$ 
Figure 4 shows the calculated ignition contours for the combustible areas for the 4 th level MTB. It can be seen that the combustible areas are sufficiently widely separated for fire spread to be unlikely even given failure of a sprinkler system. Similar calculations were carried out for the Canyon, Wing and 2nd Level Domestic Lobby but are not presented here due to constraints on space.

\section{Moveable Fire Load}

In addition to fire spread from areas of fixed fire load there is potential within a transport terminal for fire spread to and from items of baggage which may be regarded as a moveable fire load. It is helpful to estimate the likely distribution of this combustible material to see how it affects the Island Concept.

It is assumed that each passenger has baggage and peak values of population are given in Table 3 as calculated under Japanese Law. (The Wing need not be considered here since passengers have only hand baggage with very low fire load.) The minimum distance which might be expected between passengers is shown in the final column of Table 3 . At the time of a fire, the majority of escaping passengers will take their baggage with them. The mean distance between remaining isolated baggage items is therefore likely to be far in excess of the figures shown in Table 3.

For a baggage fire, assumed to be $1 \mathrm{~m}$ diameter, the $20 \mathrm{~kW} \mathrm{~m}^{-2}$ contour line can be calculated by assuming a conical flame of height given by equation (4) and a steady Type 1 fire. This indicates that at a centre-to-centre separation of greater than $1.8 \mathrm{~m}$, ignition of adjacent combustible material will not occur. This is less than the minimum separation distance of $2.1 \mathrm{~m}$ calculated for items of baggage above.

Therefore it may be concluded that though fire spread might occur between some items of baggage located very close together, large scale spread of fire in the open areas by this means is not expected.

\begin{tabular}{||l|c|c|c|c|c||}
\hline Area & Population & $\begin{array}{l}\text { Mean } \\
\text { population } \\
\text { density } \\
\mathrm{m}^{2} / \text { person }\end{array}$ & $\begin{array}{l}\text { Peak } \\
\text { population } \\
\text { density } \\
\mathrm{m}^{2} / \text { person }\end{array}$ & $\begin{array}{l}\text { Mean } \\
\text { separation } \\
\text { distance } \\
\mathrm{m}\end{array}$ & $\begin{array}{l}\text { Minimum } \\
\text { separation } \\
\text { distance } \\
\mathrm{m}\end{array}$ \\
\hline $\begin{array}{l}\text { MTB } \\
\text { Level 4 }\end{array}$ & 2750 & 10.3 & 7.2 & 3.2 & 2.7 \\
\hline Canyon & 1559 & 6.5 & 4.6 & 2.5 & 2.1 \\
\hline $\begin{array}{l}\text { Domestic } \\
\text { Lobby } \\
\text { Level 2 }\end{array}$ & 1134 & 6.3 & 4.4 & 2.5 & 2.1 \\
\hline
\end{tabular}

TABLE 3. Population densities in open areas

\section{SUMMARY}

One of the functions of compartmentation is to restrict the spread of fire between areas of combustible material. It has been shown here that even without compartment walls, fire spread can be shown to be restricted to the area of the origin. Effective compartmentation is achieved by ensuring that there are large distances 
between areas of combustible material, and that areas of high fire load are independently protected. The high roof ensures that flashover is not a problem in the open spaces.

\section{ACKNOWLEDGEMENTS}

Thanks are due to Margaret Law of Arup Research and Development for helpful discussions and for providing the data collected in Figure 3.

\section{REFERENCES}

[1] "Integrated Design Method for Fire Protection". Japan Building Centre, Tokyo (1989)(in Japanese)

[2] Alpert R.L. and Ward E.J. Fire Safety Journal, 7, 127, (1984)

[3] Alpert R.L. Fire Technology, 8, 181 (1975).

[4] Evans D.D. "The SFPE Handbook of Fire Protection Engineering". Dinenno P.J. (ed), NFPA, Quincy MA 1-138 (1988)

[5] Heskestad G. and Bill R.G. Fire Safety Journal, 14, 113 (1988).

[6] Heskestad G. Fire Safety Journal, 7, 25 (1984).

[7] Babrauskas V. "Will the second item ignite". Report NBSIR 81-2271, NIST, Gaithersburg, MD (1981).

[8] Tien C.L., Lee K.Y. and Stretton A.J. "The SFPE Handbook of Fire Protection Engineering". Dinenno P.J. (ed), NFPA, Quincy MA 1-92 (1988)

[9] Law, M. Private communication.

[10] "Design Guide: Structural Fire Safety". CIB, Fire Safety Journal 10, (1985).

[11] Thomas P.H. Combustion and Flame 5, (1961).

[12] Kruppa J. and Lamboley G. "Contribution à l'étude des incendies dans les bâtiments de grand volume realisés en construction metallique". Service Incendie Doc. No. 1016-5, CTICM, Puteaux (1983).

[13] Thomas P.H. Fire Research Note 841, Fire Research Station, Borehamwood UK (1961)

[14] Broido A and McMasters A.W. "Effects of Mass Fires on Personnel in Shelters". Forestry Service, US Dept Agriculture, Berkeley CA.

\section{NOMENCLATURE}

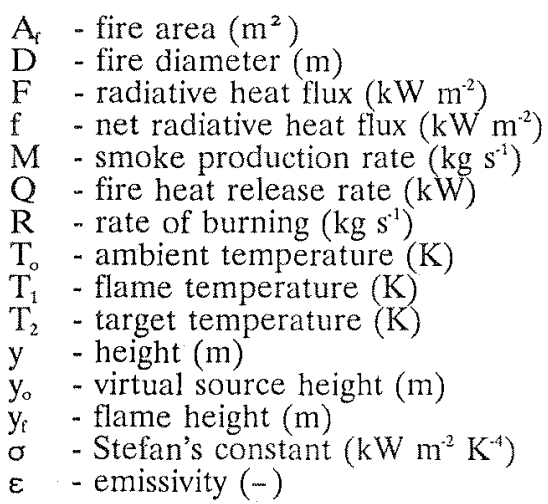

